\title{
A Desonestidade em Ciência
}

«Sei dos que praticavam o mal para que nos séculos futuros resultasse o bem, ou tivesse resultado nos já passados..." (Jorge Luís Borges, O Imortal).

Cometer uma fraude é mentir sobre um facto com o propósito de beneficiar dessa mentira. A fraude pode tomar muitas formas, mesmo em Ciência.

O tipo de fraude mais conhecido, e talvez mais nocivo, consiste na falsificação de resultados experimentais. Casos deste tipo têm aumentado nas últimas décadas, em especial nas ciências biomédicas $[1,2]$. Se a falsificação é bem feita, há poucas possibilidades de um referee a detectar. Contudo nem sempre assim é. No célebre caso Darsee [1], um dos mais de cem artigos contendo dados imaginários, publicado na prestigiada revista New England Journal of Medicine, debruça-se sobre a incidência de uma doença cardíaca rara numa familia onde um dos progenitores tinha sido pai duas vezes antes dos dez anos de idade! No entanto Darsee veio a ser desmascarado por colegas, e não por referees. $\mathrm{O}$ terceiro mecanismo de protecção contra a falsificação de resultados é a repetição. Se uma dada descoberta é realmente significativa, a sua repetição virá mais tarde ou mais cedo a ser tentada por outrém. Mas quanto do que se publica tem eco suficiente para justificar uma verificação, tarefa aliás menos compensadora do que a obtenção de resultados «novos»?

Os estudos do psicólogo S. Breuning [3], indicando que as drogas anti-psicóticas deviam ser abandonadas a favor das drogas estimulantes no tratamento de crianças diminuídas mentais hiperactivas, foram oficialmente tidos em conta em vários estados norte-americanos antes de se descobrir que tais conclusð̃es eram baseadas em dados forjados, e portanto sem qualquer valor!

$\mathrm{O}$ aumento do número de fraudes conhecidas não parece ser devido a uma maior eficácia na sua detecção, nem tão pouco apenas ao crescimento da comunidade científica. A pressão para publicar parece ser um factor-chave $[1,2,4]$, embora um substrato psíquico patológico propicie a eclosão do fenómeno [2,5]. Mas a desonestidade científica não se esgota na falsificação de dados. Como o sistema científico de comunicação envolve editores, referees e autores, a desonestidade pode ser cometida por qualquer das três categorias.

Alguns exemplos:

- Um editor ou referee pode retardar a publicação de um artigo sobre um assunto no qual é especialista, e publicar ele próprio essencialmente o mesmo e aparentemente em primeiro lugar, noutra revista. Qualquer investigador ouviu já referências a casos deste tipo, se é que não se defrontou directamente com eles.
- Um autor pode omitir do seu artigo pormenores experimentais suficientes para tornar muito difícil ou mesmo impossível a repetição controlada das experiências descritas. Muitas vezes esta omissão propositada não se destina a ocultar a existência de dados falsos, mas antes a manter grupos concorrentes à distância.

- Ser-se co-autor, ou aceitar-se ou pedir-se a co-autoria quando a participação no trabalho publicado seja insignificante ou nula. A chamada co-autoria honorária pode surgir pelo menos de duas maneiras:

- como contrapartida pela utilização de equipamento ou reagentes

- por uma relação hierárquica ou administrativa.

A prática de o chefe de grupo ou laboratório apôr o seu nome em todas as publicaçðes dos seus colaboradores pode ser imposta (moeda de troca para subsistência material) ou, mais raramente, desejada (inclusão de um nome consagrado). Segundo a revista Nature [6], enquanto a co-autoria honorária como contrapartida é muito comum, a co-autoria honorária por via hierárquica tende a desaparecer, subsistindo como norma apenas em alguns laboratórios da Índia.

A American Chemical Society publicou em 1985 um conjunto de Directrizes Éticas (Ethical Guidelines) para editores, autores e referees [7].

\footnotetext{
a Dep. Química, IST.

1. W.W. Stewart, N. Feder, Nature, 325, $207-214$ (1987).

2. D. Sharp (entrevista), La Recherche, 19, 240-244 (1988).

3. C. Holden, Science, 235, 1566-1567 (1987).

4. A. Shamoo, Z. Annau, Nature, 327, 550 (1987).

5. V. Herbert, Chem. Eng. News, 23 Nov. de 1987, p. 3.

6. Nature, 325, 181-182 (1987).

7. Acc. Chem. Res., 18, 355-357 (1985).
} 


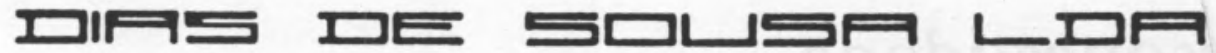 INSTRUMENTAÇ̃̃O ANALITTICA}

Distribuidores exclusivos em Portugal de:

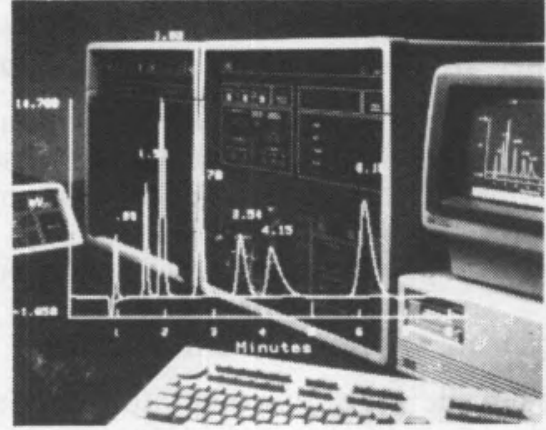

Cromatografia Iónica

DiONEX

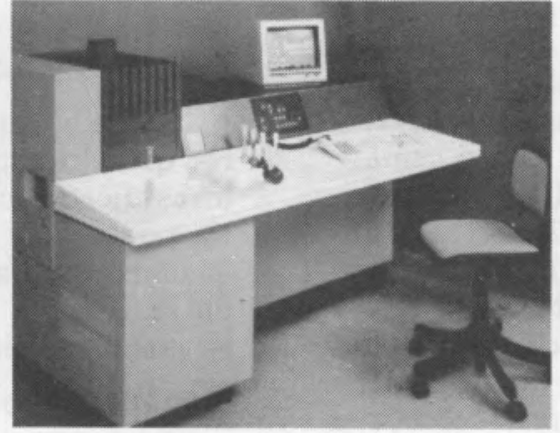

Espectrometria de Emissão

V. Jobin Yvon

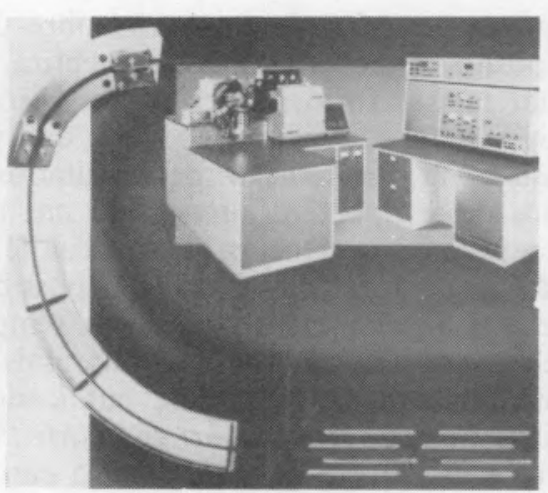

Espectrometria de Massa

FRATros

ANALYTICAL

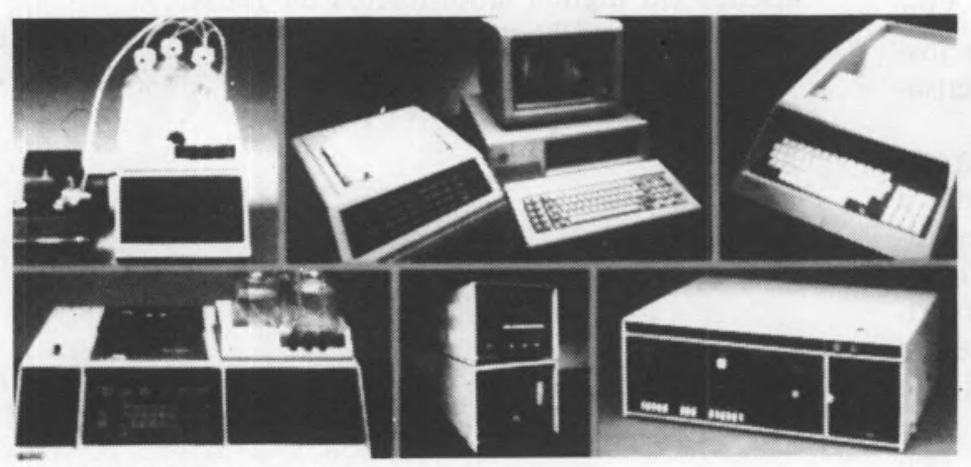

Cromatografia HPLC

Integradores-Registadores computarizados

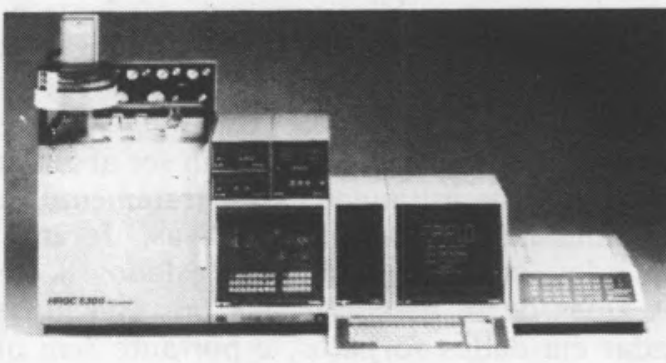

Instrumentação Cientifica

\section{CARLO ERBA}

STRUTERTAZIONE

\section{(G) Spectra-Physics}

Ao vosso serviço com Seriedade, Apoio Técnico e Analítico especializado, Enquadramento laboratorial.

QUINTA DA PIEDADE, LOTE $12 \cdot 1 .^{\circ} \mathrm{D}$. 2625 PÓVOA DE STA. IRIA

TEL. (01) $2592316-2592409$

TLX. 43926 DISO P
PRAÇA PEDRO NUNES, 94 4000 PORTO

TEL. (02) 931499 - 933809

TLX. 26250 NSC P 